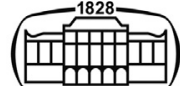

AKADÉMIAI KIADÓ

Pollack Periodica

An International Journal

for Engineering and Information Sciences

16 (2021) 3, 39-44

DOI:

10.1556/606.2021.00363

(c) 2021 The Author(s)

\section{ORIGINAL RESEARCH}

PAPER

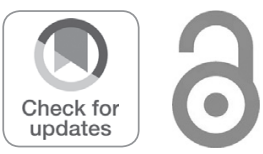

Corresponding author.

E-mail: jarmai@uni-miskolc.hu

\title{
Optimization of asymmetric I-beams for minimum welding shrinkage
}

\author{
Károly Jármai* @ and Máté Petrik @
}

Faculty of Mechanical Engineering and Informatics, Institute of Energy and Chemical Machinery, University of Miskolc, Egyetemváros, H-3515, Miskolc, Hungary

Received: December 31, 2020 • Revised manuscript received: March 29, 2021 • Accepted: March 31, 2021 Published online: May 29, 2021

\begin{abstract}
A calculation system has been developed to determine the optimum dimensions of asymmetric I-beams for minimum shrinkage. The objective function is the minimum mass; the unknowns are the I-beam dimensions; the constraints are the stress, local buckling, and deflection. Different steel grades have been considered (235, 355, $460(\mathrm{MPa})$ yield stress) and other aluminum alloys (90, 155, 230 (MPa) yield stress). The material, the span length, the loading, and the applied heat input have been changed. It is shown, that using optimum design; the welding shrinkage can be reduced with prebending and can save material cost as well.
\end{abstract}

\section{KEYWORDS}

welded structures, optimization, welding shrinkage, steel and aluminum

\section{INTRODUCTION}

When steel structures are constructed by welding, deformations and residual welding stresses could occur due to the high heat input and subsequent cooling [1]. The welding process can create significant locked-in stresses and deformations in fabricated steel structures $[2,3]$.

These adversely affect the structure's operation because tensile stresses increase the rate of fatigue crack propagation and compressive stresses reduce the flexural strength of the compressed bars and the buckling strength of the plates and shells. Warps can result in dimensionally inaccurate structural elements and scrap. Therefore, it is necessary to estimate their magnitude in advance by calculating and applying ex-ante or ex-post reduction procedures.

The residual stresses and initial imperfections can influence the structure's behavior under compression [4]. It is well known that these initial imperfections due to welding reduce the structure's ultimate strength. Even though various efforts have been made in the past to express the deflection of panels from experimental aspects and measurements of actual structures, it may be said that there are few investigations from the theoretical point of view. For higher heat, the behavior of the steel is even more complicated $[5,6]$.

\section{CALCULATION METHOD}

In the books [7-10] different computational procedures have been developed. Okerblom provided relatively simple formulas for calculating shrinkage and warping from longitudinal welds of straight bars, which can be used well for preliminary estimates, so they were adapted [11].

For the $A_{T}$ shrinkage heat pulse, Okerblom derived the following formula:

$$
A_{T}=\frac{0.4840 \alpha_{o} Q_{T}}{c_{o} \rho t} \ln 2=\frac{0.3355 \alpha_{o} Q_{T}}{c_{o} \rho t},
$$


where $Q_{T}=\eta_{0} \frac{U I_{w}}{v_{w}}=q_{o} A_{w}$ is the heat load; $U$ is the voltage; $I_{w}$ is the current; $v_{w}$ is the welding speed; $c_{o}$ is the specific heat; $\eta_{o}$ is the thermal efficiency; $q_{0}$ is the specific heat per unit weld cross-section $\left(\mathrm{J} / \mathrm{mm}^{3}\right) ; A_{w}$ is the cross-sectional area of the weld.

This formula contains the welding parameters and the base material's characteristics, so it is very well applicable to materials other than steel, e.g. aluminum alloy. For welded structures $\alpha_{o}=12 \cdot 10^{-6}\left(1 / \mathrm{C}^{\circ}\right), c_{o} \rho=4.77 \cdot 10^{-3}\left(\mathrm{~J} / \mathrm{mm}^{3} / \mathrm{C}^{\circ}\right)$, so $A_{T} t=0.844 \cdot 10^{-3} Q_{T}$.

The basic Okerblom formulas for the specific shrinkage and warp curvature of the center cross-section fiber of the $\operatorname{rod}$

$$
\begin{gathered}
\varepsilon_{G}=\frac{A_{T} t}{A}=-0.844 \cdot 10^{-3} \frac{Q_{T}}{A}, \\
C=\frac{A_{T} t y_{T}}{I_{x}}=-0.844 \cdot 10^{-3} \frac{Q_{T} y_{T}}{I_{x}} .
\end{gathered}
$$

The minus symbol refers to shrinkage. The equation of $Q_{T}$ can be changed

$$
Q_{T}=\eta_{0} \frac{U I_{w}}{v_{w}}=\eta_{0} \frac{3600 U \rho}{\alpha_{N}} A_{w},
$$

where $I_{x}$ is the moment of inertia; $\rho=7.85 \cdot 10^{-6}\left(\mathrm{~kg} / \mathrm{m}^{3}\right)$ is the density of the steel; $\alpha_{N}=8.8 \cdot 10^{-3}(\mathrm{~kg} / \mathrm{Ah})$ is the fusion factor. With the above values $U=27(\mathrm{~V}), \eta_{0}=0.7$. The heat input for fillet welds, for butt welds and for submerged arc welds are as follows

$$
Q_{T}=60.7 A_{w}, \cdots Q_{T}=78.8 A_{w}, \cdots Q_{T}=59.5 A_{w} .
$$

The residual compressive stress can be calculated

$$
\sigma_{c}=\frac{A_{T} t f_{y}}{A \varepsilon_{y}}=\frac{A_{T} t}{A} E=\frac{0.3355 \alpha_{o} \eta_{o} U I E}{c_{o} \rho v_{w} b t},
$$

where $A$ is the cross-section area, $b$ is the plate width, $t$ is the plate thickness, $E$ is the Young modulus.

This Okerblom formula has been compared with that proposed one by [12] with the data he used $\alpha_{o}=11 \cdot 10^{-6}$; $c_{o} \rho=3.53 \cdot 10^{-3}\left(\mathrm{~J} / \mathrm{mm}^{3}{ }^{\circ} \mathrm{C}\right) ; E=2.05 \cdot 10^{5}(\mathrm{MPa}) ; v_{w}$ is the welding speed. According to the Okerblom equation

$$
\sigma_{c}=\frac{0.214 \eta_{o} U I}{v_{w} b t} \text {. }
$$

The proposed White's [12] formula for single-pass welding based on his own experiments

$$
\sigma_{c}=\frac{0.2 \eta_{o} U I}{v_{w} b t}
$$

It can be seen that Okerblom's formula agrees well with White's experimental results.

\section{EFFECT OF INITIAL STRAIN}

In the calculations so far, it was assumed that there are no initial deformations in the structural part to be welded structure. In the case of multiple welds, these deformations may occur or may be caused by the previous welds. Preheating, flame-cutting, or pre-stressing can generate these. The modifying factor $\nu_{m}$ considers the effect of these. This is the quotient of the heat load with and without the initial elongation.

$$
\nu_{m}=\frac{A_{T}^{\prime}}{A_{T}}=1-\frac{\ln \left(1+\frac{\varepsilon_{I}}{\varepsilon_{y}}\right)}{\ln 2} \approx 1-\frac{\varepsilon_{I}}{\varepsilon_{y}} .
$$

The approximate formula is valid for the initial tensile specific elongation, that is, if $\varepsilon_{I} / \varepsilon_{y} \geq 0$. The modifying factor can be used to determine the correct welding sequence in simpler cases. The deformation after the first weld can be calculated as follows

$$
\varepsilon_{G 1}=\frac{A_{T 1} t}{A}, \quad C_{1}=\frac{A_{T 1} t y_{T}}{I_{x}} .
$$

The strain at the other weld place (before it has been made) is as follows

$$
\varepsilon_{I 12}=\varepsilon_{G 1}+C_{1} y_{2}=A_{T 1} t\left(\frac{1}{A}+\frac{y_{1} y_{2}}{I_{x}}\right) .
$$

The modifying parameter

$$
\nu_{m 12}=1-\frac{\ln \left(1+\frac{\varepsilon_{I 12}}{\varepsilon_{y}}\right)}{\ln 2} \approx 1-\frac{\varepsilon_{I 12}}{\varepsilon_{y}} .
$$

The total strain and curvature after both welds have been made

$$
\begin{gathered}
\varepsilon_{G(1+2)}=\varepsilon_{G 1}+\nu_{m 12} \varepsilon_{G 2}=\varepsilon_{G 1}\left(1+\nu_{m 12} \frac{Q_{T 2}}{Q_{T 1}}\right), \\
C_{1+2}=C_{1}+\nu_{m 12} C_{2}=C_{1}\left(1+\nu_{m 12} \frac{Q_{T 2} y_{2}}{Q_{T 1} y_{1}}\right) .
\end{gathered}
$$

In the case of an asymmetric I-beam, the welding parameters that allow the warps from the two welds to be zero are defined. The welding shrinkage is always larger at asymmetric than symmetric beams.

\section{REDUCTION OF RESIDUAL STRESSES AND STRAINS}

Preventive methods: symmetrical weld arrangement, design of appropriate welding sequence, welding in the clamping device, application of pre-bending, preheating. Subsequent methods: straightening, vibration [13] heat treatment, treatment of the weld edge by Tungsten Inert Gas (TIG) or plasma arc melting, hammering, shot peening, ultrasonic treatment.

\subsection{Welding in an elastically pre-bent state in a clamping device}

The production sequence: tacking, pre-bending, clamping, welding, and loosening (Fig. 1). 


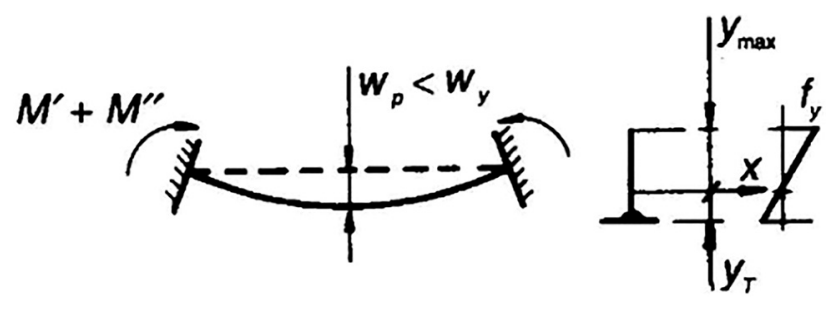

Fig. 1. Welding in a pre-bent state in a clamping device

To prevent substantial deformations and cracks, it is advisable to use pre-bending moments not larger than

$$
M_{y}=\frac{f_{y} I_{x}}{y_{\max }} .
$$

The curvature and deformation caused by $M_{y}$ are

$$
C_{y}=\frac{M_{y}}{\mathrm{EI}_{x}}, \quad w_{y}=\varepsilon_{y} \frac{L^{2}}{8 y_{\max }} .
$$

The pre-bending $w_{p}<w_{y}$ causes a tensile pre-strain in the place of the longitudinal weld

$$
\varepsilon_{p}=C_{p} y_{T}=w_{p} \frac{8 y_{T}}{L^{2}},
$$

the corresponding modifying factor is

$$
\nu_{m}=1-\frac{\varepsilon_{p}}{\varepsilon_{y}} .
$$

The bending moment necessary to keep straight the beam after welding consists of two parts as follows: the moment which is required for pre-bending

$$
M^{\prime}=I_{\zeta} \mathrm{EC}_{p}=8 w_{p} \frac{E I_{\zeta}}{L^{2}}
$$

and the moment, which is necessary to eliminate the residual welding deformations

$$
M^{\prime \prime}=\nu_{m} I_{\zeta} \mathrm{EC}=8 \nu_{m} w \frac{E I_{\zeta}}{L^{2}}
$$

These moments act opposite after the loosening and decrease the pre-bending deformations,

$$
M=M^{\prime}+M^{\prime \prime}=I_{\zeta} \mathrm{EC}_{p}+\nu_{m} I_{\zeta} E C,
$$

so that the remaining final deformations can be expressed as

$$
\begin{gathered}
w_{f}=w-w_{p}=\frac{M^{\prime}+M^{\prime \prime}}{8 \mathrm{EI}_{x}} L^{2}-w_{p}, \\
w_{f}=\left(w_{p}+\nu_{m} w\right) \frac{I_{\zeta}}{I_{x}}-w_{p}
\end{gathered}
$$

where $\nu_{m}=1-8 w_{p} y_{t} /\left(L^{2} \varepsilon_{y}\right) ; I_{x}$ is the moment of inertia for the elastic section area. $I_{\xi}$ is the moment of inertia for the elastic section area, reduced by the plastic zone, $C$ is the curvature of the beam caused by welding in a free state, $\nu_{m}$ is the correction parameter, according to Eq. (12).

The pre-bending $w_{p}$ necessary to totally eliminate the residual welding deformations can be calculated from the condition $w_{p}=0$,

$$
w_{p}=\frac{w}{\frac{I_{x}}{I_{\zeta}}+\frac{8 y_{T} w}{L^{2} \varepsilon_{y}}-1} .
$$

\section{NUMERICAL EXAMPLES FOR WELDING IN A PRE-BENT STATE IN A CLAMPING DEVICE}

Let us consider an asymmetric I-section beam in Fig. 2 .

There is one welding joint at the section. Given parameters are as follows for the welded beams: length of the beam $L$ in (m), changing between 5-10 (m); uniformly distributed force $F$ in $(\mathrm{N})$, changing between 10,000-100,000 (N); Young modulus $E$ in $(\mathrm{MPa})$, for steels $210(\mathrm{GPa})$, for aluminum $70(\mathrm{GPa})$; yield stress of the steel $f_{y}$ in $(\mathrm{MPa})$, changing between 235-460 (MPa), for aluminum 80-230 $(\mathrm{MPa})$; the density of the material is $\rho$ in $\left(\mathrm{kg} / \mathrm{m}^{3}\right)$, for steels $7,850\left(\mathrm{~kg} / \mathrm{m}^{3}\right)$, for aluminum $2,700\left(\mathrm{~kg} / \mathrm{m}^{3}\right)$; specific heat $c$ in $(\mathrm{J} / \mathrm{kgK})$, for the steel $c=510(\mathrm{~J} / \mathrm{kgK})$, for the aluminum $c=910(\mathrm{~J} / \mathrm{kgK})$; thermal expansion parameter $\alpha$ in $\mathrm{K}$, for steels $\alpha=11 \cdot 10^{-6}(\mathrm{~K})$, for aluminum $\alpha=22 \cdot 10^{-6}(\mathrm{~K})$.

The sizes of the cross-section are the following: $b_{1}$ is the width of the upper flange; $t_{1}$ is the width of the upper flange; $h$ is the height of the web; $t$ is the thickness of the web; $b_{2}$ is the width of the lower flange; $t_{2}$ is the width of the lower flange (Table 1).

Input data: $L=10(\mathrm{~m}) ; F=98,100(\mathrm{~N}) ; f_{y}=460(\mathrm{MPa})$; the plate's angle before welding is $\beta=50^{\circ}$; the applied heat input is $60,700\left(\mathrm{~J} / \mathrm{m}^{3}\right)$, the applied standard is Eurocode 3 [14].

The optimum has been calculated using Excel, the results are visible in Table 1.

The moment of inertia: $I_{x}=1.6008 \cdot 10^{8}\left(\mathrm{~mm}^{4}\right)$, the crosssection area: $A=6228.504\left(\mathrm{~mm}^{2}\right)$. The pre-bending value, according to Eq. (24) is as follows

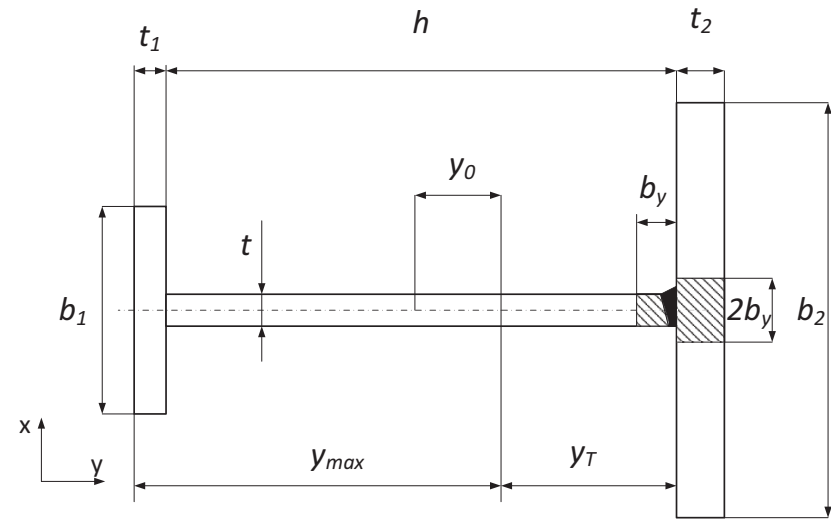

Fig. 2. The cross-section of the welded I-beam

Table 1. Optimized results for a steel beam in ( $\mathrm{mm})$, the beam is fixed at both ends during production (prebent)

\begin{tabular}{lccc}
\hline$b_{1}$ & 188.67685 & $t$ & 7.3591728 \\
$t_{1}$ & 9.427696 & $b_{2}$ & 188.67685 \\
$h$ & 362.93855 & $t_{2}$ & 9.4276958 \\
\hline
\end{tabular}




$$
w_{f}=0, \quad w_{p}=\frac{w}{\frac{I_{x}}{I_{\zeta}}+\frac{8 y_{T} w}{L^{2} \varepsilon_{y}}-1},
$$

where $y_{T}$ is the distance of the weld from the gravity center of the cross-section, $\varepsilon_{y}$ is the strain belongs to yield stress. With the data $y_{T}=181.469(\mathrm{~mm}) ; w=26.83 \quad(\mathrm{~mm})$; $\varepsilon_{y}=2.19 \cdot 10^{-3} ; w_{P}=61.975(\mathrm{~mm})$.

The pre-bending should be in the elastic zone. The limit pre-bending deflection is as follow:

$$
w_{y}=C_{y} \frac{L^{2}}{8}=\varepsilon_{y} \frac{L^{2}}{8 y_{\max }}=143.43(\mathrm{~mm}),
$$

where $y_{\max }=190.89(\mathrm{~mm})$. Since the pre-bending deflection $w_{P}$ is less than the yield deflection. So the result is suitable.

\section{OPTIMIZATION FOR MINIMUM MASS}

The optimization is made by the generalized reduces gradient technique, built-in Excel Solver. The objective function to be minimized is the mass of the welded beam. The unknowns are the six sizes of the cross-section $b_{1}, t_{1}, h$, $t, b_{2}, t_{2}$.

Constraints are:

- static stress, the limit is $f_{y} / 1.5$;

- local buckling constraint according to Eurocode 3 and 9 $[14,15]$, for steel for flanges $b / t_{f} \leq 1 / \delta=28 \varepsilon$, for webplate $h / t_{w} \leq 1 / \beta=69 \varepsilon$, and $\varepsilon=\sqrt{235 \mathrm{MPa} / f_{y}}$ and for aluminum $b / t_{f} \leq 1 / \delta=4 \varepsilon$ for flanges and $h / t_{w} \leq 1 / \beta=15 \varepsilon$ for webplate, where $\varepsilon=\sqrt{250 \mathrm{MPa} / f_{y}}$;

- deflection constraint Eqs (10), (35).

During optimization, the material (steel, aluminum), the yield stress 235, 355, $460(\mathrm{MPa})$ for steel, 90, 155, $230(\mathrm{MPa})$ for aluminum, the span length $5(\mathrm{~m}), 10(\mathrm{~m})$ and the heat input (for steel 12.5, 60.7, $91.8\left(\mathrm{~kJ} / \mathrm{m}^{3}\right)$, for aluminum 14,45 , $61.2\left(\mathrm{~kJ} / \mathrm{m}^{3}\right)$ have been considered and compared.

\section{OPTIMIZATION RESULTS}

For the steel, the optimum results are as follows using different steel grades and span length. The heat input is 60.7 $\left(\mathrm{kN} / \mathrm{m}^{3}\right)$.

Figure 3 shows that the cross-section is near linearly proportional to the loading, but the increment depends on the span length. If one double-span length, the cross-section, so the mass of the beam does not double. Using higher strength steel, one can save material. The material savings are $21.4 \%$ using $f_{y} 355(\mathrm{MPa})$ instead of $235(\mathrm{MPa})$ and $31.4 \%$ using $f_{y} 460$ (MPA) instead of 235 (MPa) steel.

For the aluminum, the results are as follows using different alloys.

Figure 4 shows that the cross-section is linearly proportional to the loading using aluminum, but the increment depends on the span length. The applicable load is limited; it cannot go up to $100(\mathrm{kN})$.

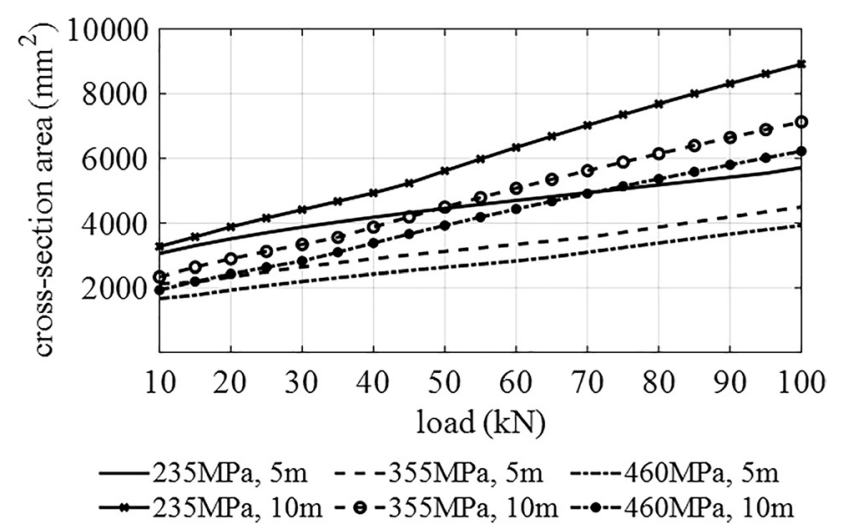

Fig. 3. Optimum results for different steel grades and span lengths, heat input is $60.7\left(\mathrm{kN} / \mathrm{m}^{3}\right)$.

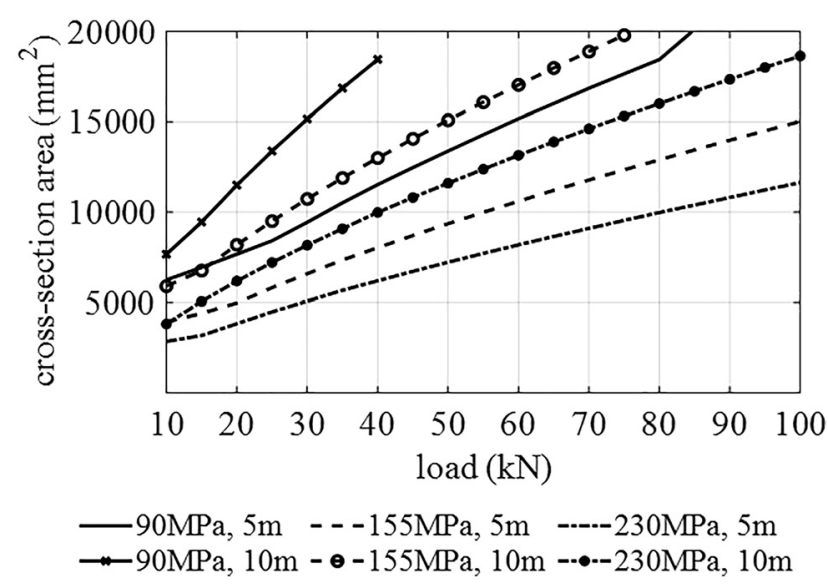

Fig. 4. Optimum results for different aluminum alloys and span lengths, heat input is $45\left(\mathrm{kN} / \mathrm{m}^{3}\right)$

At the lighter aluminum, the stability constraint has a high effect on larger span length. Using higher strength aluminum, one can save material. The material savings are $54.5 \%$ using $f_{y} 155(\mathrm{MPa})$ instead of $90(\mathrm{MPa})$ and $64.8 \%$ using $f_{y} 230(\mathrm{MPa})$ instead of $90(\mathrm{MPa})$ aluminum. For larger span length, the optimum cross-section value is jumping due to the local buckling limit.

Having smaller heat input for steel, $12.5\left(\mathrm{~kJ} / \mathrm{m}^{3}\right)$ the tendency is different. The cross-section areas increase not linearly, but smaller, applying larger loads (Fig. 5). The effect is similar to aluminum, with $14\left(\mathrm{kN} / \mathrm{m}^{3}\right)$ heat input (Fig. 6).

The heat input depends on the voltage, current, welding speed, and the welding technology's efficiency. In most cases, the applied current and the welding speed can be changed. For smaller energy input, the results are different for both materials For higher heat input (Figs 7 and 8) give the results.

At the smaller heat input for aluminum, $14\left(\mathrm{~kJ} / \mathrm{m}^{3}\right)$, the tendency is different (Fig. 6). There are solutions for $L=10(\mathrm{~m})$, when the force is increasing. The cross-section areas do not increase linearly, but smaller, applying larger loads. For the $A l 230(\mathrm{MPa})$ at $10(\mathrm{~m})$, the cross-section is $22 \%$ less, when the heat input went down from $46(\mathrm{MPa})$ to $14\left(\mathrm{~kJ} / \mathrm{m}^{3}\right)$. 


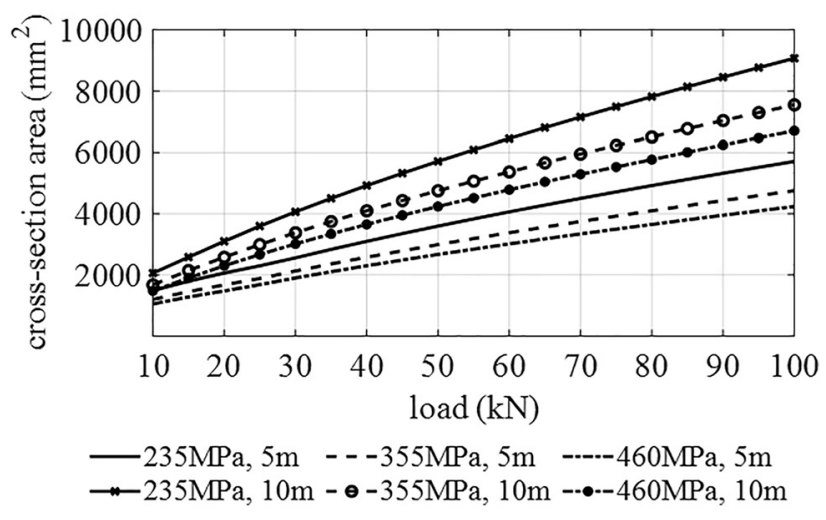

Fig. 5. Optimum results for different steel grades and span lengths, heat input is $12.5\left(\mathrm{kN} / \mathrm{m}^{3}\right)$

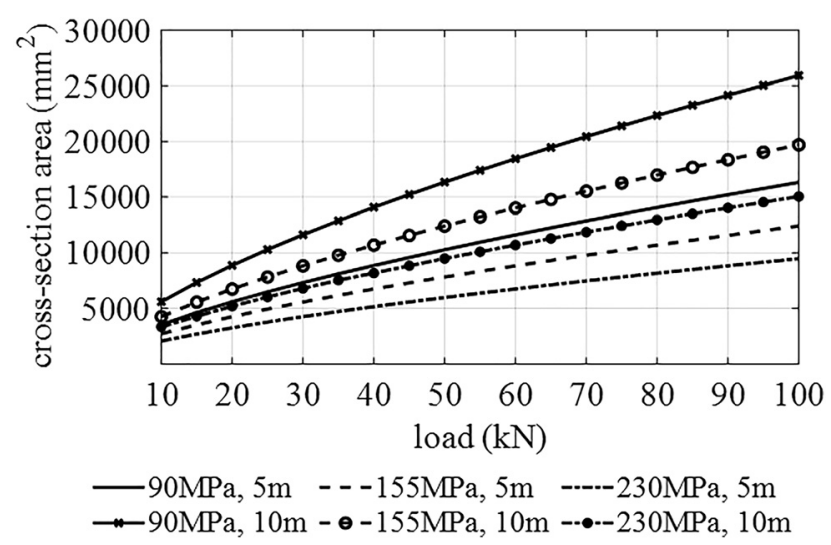

Fig. 6. Optimum results for different aluminum alloys and span lengths, the heat input is $14\left(\mathrm{kN} / \mathrm{m}^{3}\right)$

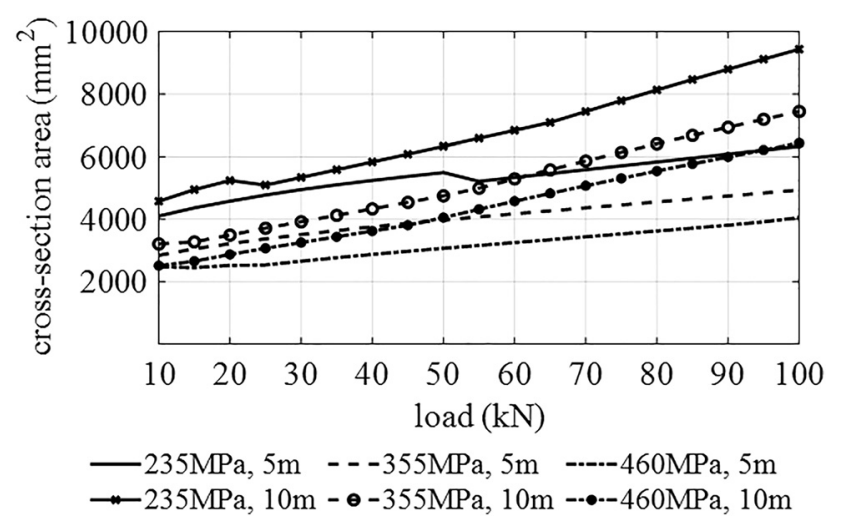

Fig. 7. Optimum results for different steel grades and span lengths, heat input is $91.8\left(\mathrm{kN} / \mathrm{m}^{3}\right)$

Figure 7 shows that the different steel grades are still applicable for larger span-lengths using higher heat input (higher current or lower welding speed). For aluminum, this is not the case. Figure 8 shows that increasing the heat input; the maximum applicable load values are very limited. For $A l$ $90(\mathrm{MPa}), 10 \mathrm{~m}$ it is only $20(\mathrm{kN})$.

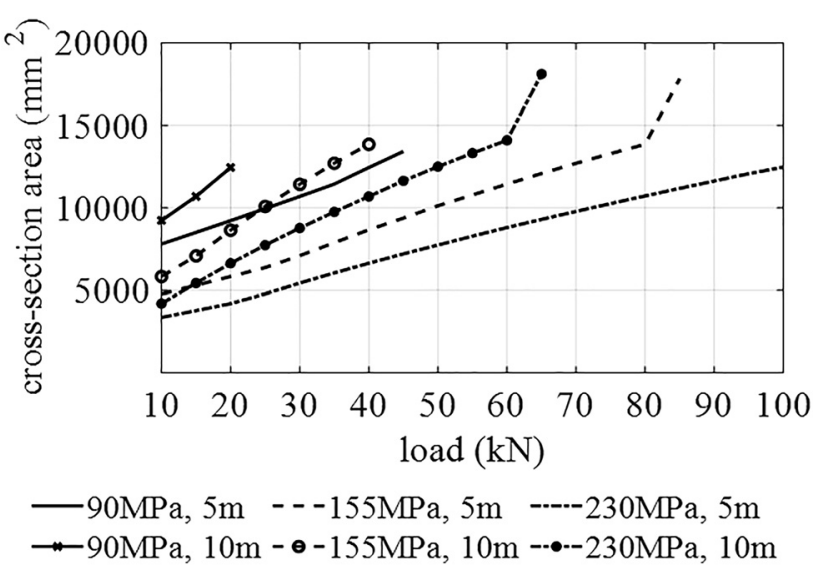

Fig. 8. Optimum results for different aluminum alloys and span lengths, heat input is $61.2\left(\mathrm{kN} / \mathrm{m}^{3}\right)$

\section{CONCLUSIONS}

This article has presented the calculation to determine the optimum dimensions of asymmetric I-beams for minimum shrinkage. The welding shrinkage is always larger at asymmetric than symmetric beams. The objective function is the minimum mass; the unknowns are the I-beam dimensions; the constraints are the stress, local buckling and deflection. Different steel grades have been considered (235, 355, 460 MPa yield stress) and different aluminum alloys (90, 155, 230 $\mathrm{MPa}$ yield stress). The material, the span length and the loading have been changed. It is shown that using prebending, welding shrinkage can be eliminated, and using optimum design, the material cost can be saved as well. During optimization the minimum sizes of the asymmetric Ibeam have been calculated. The design constraints were the static stress, local buckling of the web, flange and pre-bending to eliminate shrinkage. The material (steel, aluminum), the yield stress $(235,355,460(\mathrm{MPa})$ for steel, 90, 155, $230(\mathrm{MPa})$ for aluminum), the span length $(5(\mathrm{~m}), 10(\mathrm{~m}))$ and the heat input (for steel 12,$5 ; 60,7 ; 91,8\left(\mathrm{~kJ} / \mathrm{m}^{3}\right)$, for aluminum 14 ; $\left.45 ; 61,2\left(\mathrm{~kJ} / \mathrm{m}^{3}\right)\right)$ have been changed and compared.

The cost-saving for different steels is up to $31.4 \%$ and for other aluminum is up to $63.8 \%$. Various steel grades are more applicable for more considerable heat input and larger span-lengths. With these calculations welding shrinkage and mass of the beam can be reduced as well.

\section{ACKNOWLEDGEMENT}

The research was partially supported by the Hungarian National Research, Development and Innovation Office under the project number K 134358.

\section{REFERENCES}

[1] M. Urner, T. Welters, and K. Dilger, "Calculation of welding residual stresses and distortions under complex process conditions, 
design, fabrication and economy of welded structures," in Design, Fabrication and Economy of Welded Structures, K. Jarmai, J. Farkas, Eds., International Conference Proceedings, Miskolc, Hungary, Apr. 24-26, 2008, 2008, pp. 395-402.

[2] H. Wohlfahrt, T. Nitschkepagel, K. Dilger, D. Siegele, M. Brand, J. Sakkiettibutra, and T. Loose, "Residual stress calculations and measurements - Review and assessment of the IIW round robin results," Weld. World, vol. 56, no 9-10, pp. 120-140, 2012.

[3] A. Kawaguchi, S. Itoh, M. Mochizuki and M. Kameyama, "Largescale computation of welding residual stress," Prog. Nucl. Sci. Technol., vol. 2, pp. 613-619, 2011.

[4] K. Jármai and M. Petrik, "Optimization and comparison of different standards for compressed welded box columns," Pollack Period., vol. 15, no. 1, pp. 3-14, 2020.

[5] Z. Virág, "Determination of optimum diameter of a welded stiffened cylindrical shell," Pollack Period., vol. 4, no. 1, pp. 41-52, 2009.

[6] K. Jármai and R. Szücs, "Investigation of welded protective covers for heat treatment," Pollack Period., vol. 15, no. 1, pp. 15-26, 2020.
[7] N. O. Okerblom, V. P. Demyantsevich, and I. P. Baikova, Design of Fabrication Technology of Welded Structures (in Russian). Leningrad: Sudpromgiz, 1963.

[8] V. A. Vinokurov, Welding Stresses and Distortion: Determination and Elimination (Translated from Russian). British Library Lending Division, 1977.

[9] K. Masubuchi, Analysis of Welded Structures. Oxford: Pergamon Press, 1980.

[10] S. A. Kuzminov, Welding Deformations of Ship Structures (in Russian). Leningrad: Sudostroenie, 1974.

[11] J. Farkas and K. Jármai, "Analysis of some methods for reducing residual beam curvatures due to weld shrinkage," Weld. World, vol. 41, no. 4, pp. 385-398, 1998.

[12] J. D. White, "Longitudinal shrinkage of a single pass weld," Technical Report, No. CUED/C-Struct/TR.59 c, Cambridge University; Department of Engineering, 1976.

[13] G. P. Wozney and G. R. Crawmer, An Investigation of Vibrational Stress Relief in Steel. Defense Technical Information Center, 1968.

[14] Eurocode 3, Design of steel structures, Brussels, CEN 2009.

[15] Eurocode 9, Design of aluminum structures, Brussels, CEN 2007. 